\title{
Parathyroid adenoma with prominent lymphocytic infiltrate having histological features highly suggestive of IgG4-related disease: a case report and literature review
}

\author{
Minsun Jung ${ }^{1)}$, Jeong Mo Bae ${ }^{1)}$, Yoon Kyung Jeon ${ }^{1), 2)}$, Kyeong Cheon Jung ${ }^{1), 2)}$, Sun Wook Cho ${ }^{3)}$ and \\ Jae-Kyung Won ${ }^{1), 2)}$ \\ 1) Department of Pathology, Seoul National University Hospital, Seoul 03080, Republic of Korea \\ 2) Department of Pathology, College of Medicine, Seoul National University, Seoul 03080, Republic of Korea \\ 3) Department of Internal Medicine, College of Medicine, Seoul National University, Seoul 03080, Republic of Korea
}

\begin{abstract}
Parathyroid adenoma with prominent lymphocytic infiltrate is a rare disease. Until now, 11 patients have been reported. Herein, we report a 57-year-old man who had a neck mass that was incidentally found. Aspiration cytology and subsequent needle biopsy of the tumor were performed and suggested papillary thyroid carcinoma. From the resected specimen, however, the patient was finally diagnosed with parathyroid adenoma with prominent lymphocytic infiltrate, characterized by hyperplastic parathyroid cells with nuclear atypia within fibrotic stroma along with numerous lymphocytes forming germinal centers. Some eosinophils and plasma cells were also observed with some histological features highly suggestive of IgG4-related disease (IgG4-RD), including increased IgG4-positive plasma cells and IgG4/IgG-positive plasma cell ratio, storiform-type fibrosis, and obliterative phlebitis. It turned out that microfollicular or trabecular architecture and cellular atypia with high expression of HBME-1 observed in the aspiration cytology and needle biopsy had been misinterpreted as a thyroid malignancy. This is the first report describing microscopic features of aspiration cytology and needle biopsy of parathyroid adenoma with prominent lymphocytic infiltrate, warning that it can mimic papillary thyroid carcinoma in biopsy specimens. Furthermore, the IgG4-RD-like features of the present case and previous reports imply that parathyroid adenoma with prominent lymphocytic infiltrate may be a type of IgG4-RD.
\end{abstract}

Key words: Parathyroid adenoma with prominent lymphocytic infiltrate, Parathyroid adenoma, Parathyroid neoplasms, IgG4related disease, Papillary thyroid carcinoma

PARATHYROID ADENOMA with prominent lymphocytic infiltrate is a rare disease, characterized by prominent lymphocytic infiltration in the adenomatous parathyroid gland, which has been reported in 11 patients [1-6]. Because of its rarity, clinicopathological and immunohistochemical (IHC) characteristics of the tumor are largely unrevealed. Here we describe a patient with parathyroid adenoma with prominent lymphocytic infiltrate, including its cytomorphological characteristics in aspiration cytology and needle biopsy for the first time. The tumor showed infiltration-like pattern and diffuse expression of HBME-1 that can be a diagnostic pitfall

Submitted Oct. 5, 2018; Accepted Jan. 11, 2019 as EJ18-0428 Released online in J-STAGE as advance publication Feb. 5, 2019 Correspondence to: Jae-Kyung Won, Department of Pathology, Seoul National University Hospital, Seoul National University College of Medicine, 101 Daehak-ro, Jongno-gu, Seoul 03080, Korea. E-mail: jkyung.won@gmail.com with malignancy, such as papillary thyroid carcinoma (PTC) on needle biopsy. Furthermore, the tumor exhibited features highly suggestive of IgG4-related disease (IgG4-RD), which implied a close association between parathyroid adenoma with prominent lymphocytic infiltrate and IgG4-RD.

\section{Case Presentation}

A 57-year-old man presented a well-demarcated mass in the left thyroid, which was incidentally found during a neck ultrasonography and computed tomography (CT) in 2015 (Fig. 1a, b). Serum thyroid function tests were within normal limits. Fine needle aspiration cytology was carried out, which was diagnosed as atypia of undetermined significance. Needle biopsy was performed and PTC was suggested. In the preoperative work-up, serum calcium and PTH levels were elevated to $12.2 \mathrm{mg} / \mathrm{dL}$ 

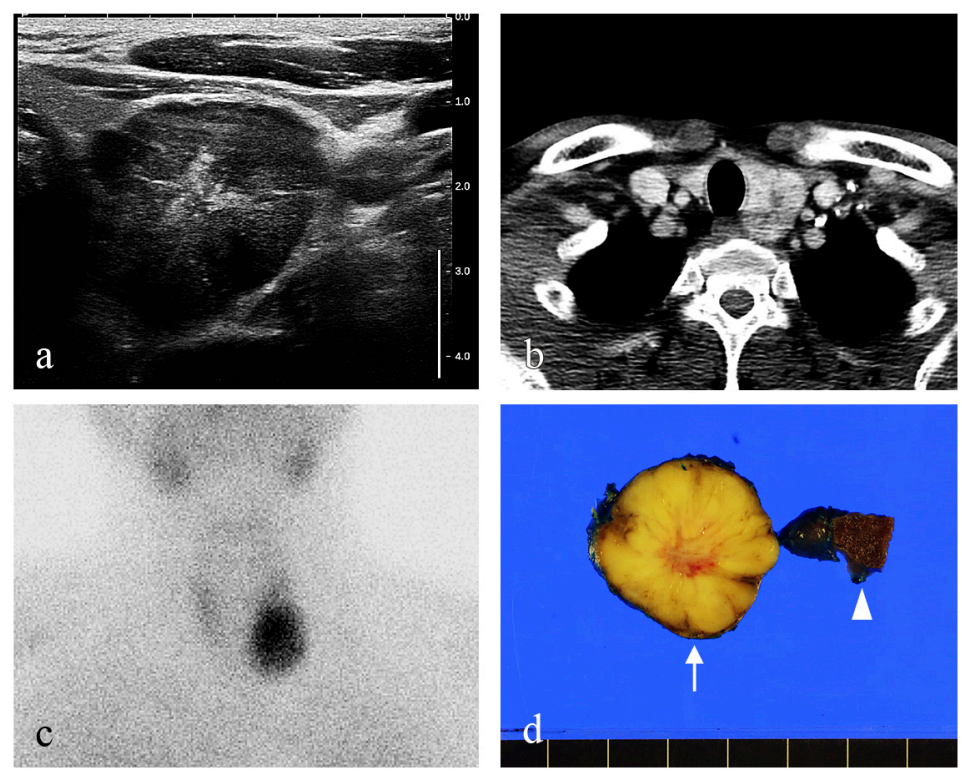

Fig. 1 The well-defined tumor is seen in ultrasonography as a hypoechoic nodule (a) and in neck CT at the left thyroid (b). A Tc-MIBI avid tumor is found in the left lower aspect of the thyroid (c). In the resected specimen, the tumor (arrow) has a tan-yellow cut surface and is separated from the thyroid (arrowhead) (d).
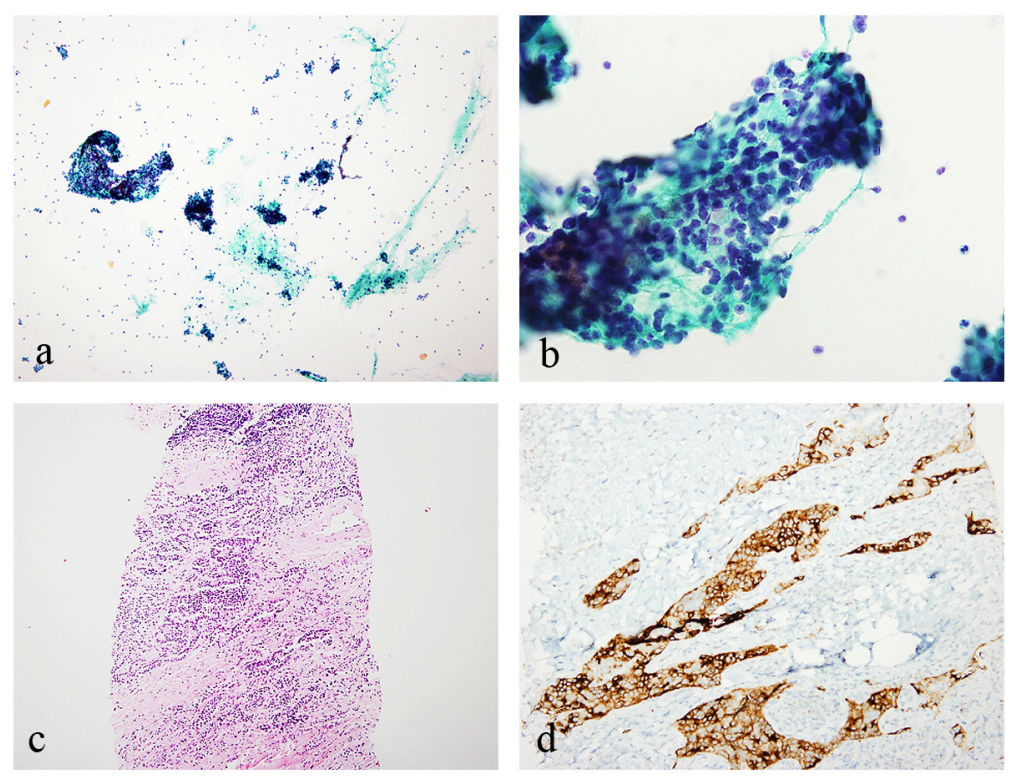

Fig. 2 The cytology specimen contains cellular aspirates in the background of inflammatory cells (a). Tumor cells with atypical crowded nuclei and oncocytic cytoplasm were arranged in microfollicular structures (b). The needle biopsy specimen shows that tumor cells infiltrate in fibrotic stroma which contains numerous lymphocytes (c). Tumor cells expressed HBME-1 in IHC staining (d).

(normal range: $8.8-10.5 \mathrm{mg} / \mathrm{dL}$ ) and $252.1 \mathrm{ng} / \mathrm{L}$ (normal range: $15-65 \mathrm{ng} / \mathrm{L})$, respectively, indicating primary hyperparathyroidism. Technetium-sestamibi SPECT/CT (Fig. 1c) demonstrated high uptake at the lower aspect of the left thyroid; however, it was inconclusive between a parathyroid lesion and PTC, as suggested from the needle biopsy. Consequently, total thyroidectomy with parathyroid exploration was carried out (Fig. 1d).

The cytology specimen showed oncocytic cells occa- sionally forming microfollicles and some inflammatory cells in the background (Fig. 2a). Nuclei of tumor cells were overlapped and had mild to moderate atypia (Fig. $2 \mathrm{~b})$. In the needle biopsy specimen, tumor cells having hyperchromatic nuclei with irregular borders showed infiltrating patterns in the fibrotic stroma (Fig. 2c). In IHC staining, tumor cells were diffuse-positive for HBME-1 (Fig. 2d).

The resected tumor measured $3.9 \times 3.0 \times 2.9 \mathrm{~cm}$ and 

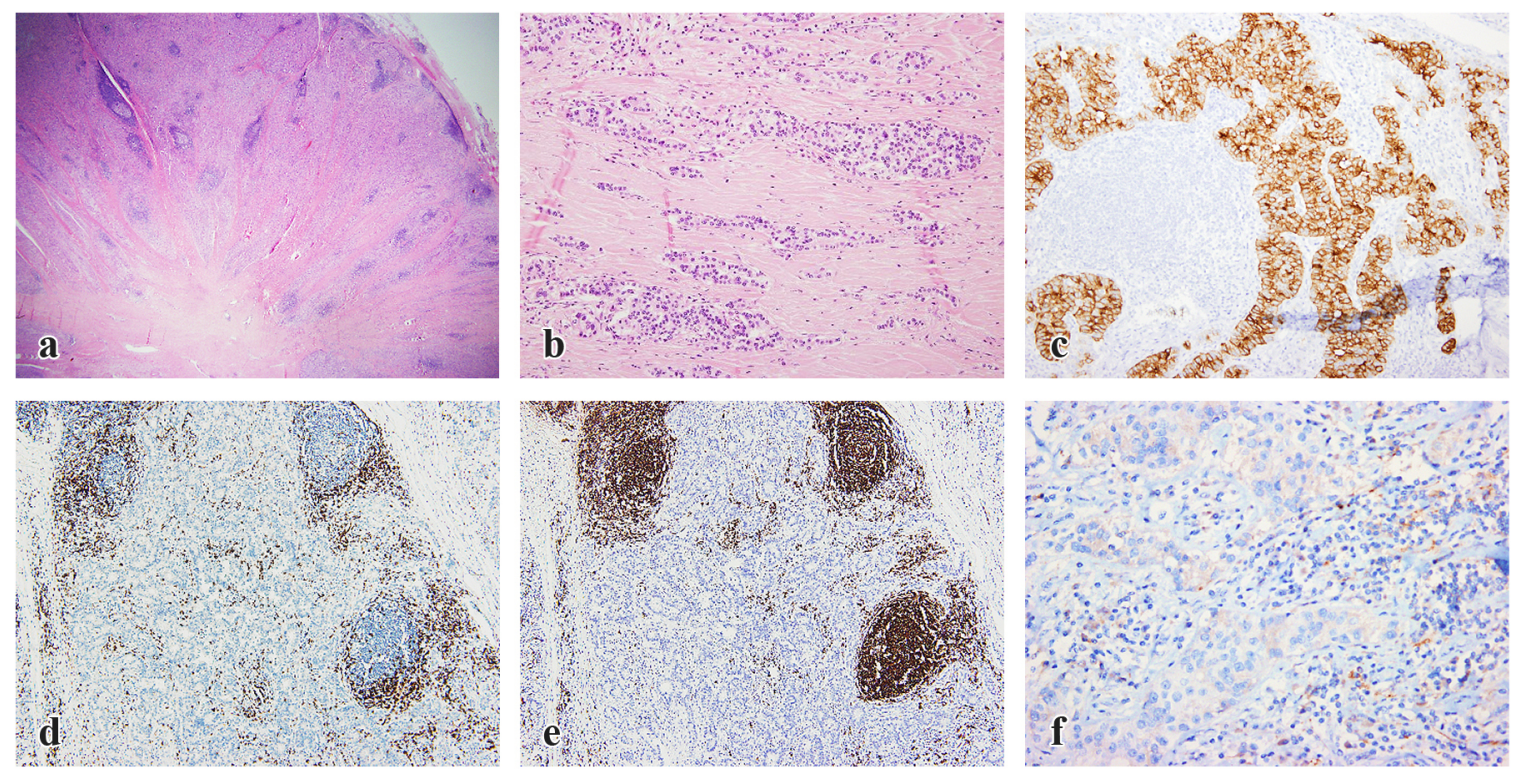

Fig. 3 The resected specimen shows well-developed germinal centers in the stroma, with band-like fibrosis (a). Tumor cells in trabecular or follicular arrangement are embedded in the abundant fibrotic stroma (b). IHC staining for PTH is diffuse-positive in tumor cells (c). IHC staining for CD3 (d) and CD20 (e) shows an intact follicular architecture and heterogeneous populations of infiltrating lymphocytes. PD-L1 is expressed mostly in stromal inflammatory cells and in a few tumor cells (1\%) (f).

was located adjacent to but separated by a fibrotic capsule from the left lower pole of the thyroid (Figs. 1d and 3a). Hyperplastic tumor cells were arranged in a trabecular or microfollicular pattern with the proportional variation of fibrotic stroma, mimicking stromal invasion (Fig. 3b). Neither capsular nor vascular invasion was observed. Tumor cells were diffuse-positive for PTH (Fig. 3c) but negative for TTF-1 or TG (figure not shown) in IHC staining. In addition, lymphocytic infiltration was prominent, forming secondary follicles with mature germinal centers (Fig. 3a, d, e), highlighted by IHC staining for CD3 (Fig. 3d) and CD20 (Fig. 3e). The $\mathrm{Ki}-67$ index was approximately $1 \%$ in tumor cells (figure not shown). PD-L1 was expressed mostly in inflammatory cells and infrequently in tumor cells (1\%) with a cytoplasmic staining pattern (Fig. 3f). In addition, infiltration of some eosinophils and plasma cells (Fig. 4a) and vague storiform-type fibrosis were observed (Fig. $4 \mathrm{~b})$. Numerous IgG4-positive plasma cells were present (>100/high-power field) (Fig. 4c), with increased IgG4/ IgG-positive plasma cell ratio (40-60\%) (Fig. 4c, d). Obliterative phlebitis was apparent on elastin staining (Fig. 4e). As a result, histopathological and IHC findings led to the diagnosis of parathyroid adenoma with prominent lymphocytic infiltrate having features highly suggestive of IgG4-RD. Lymphocytic infiltrate was absent in the contralateral parathyroid gland and in the thyroid. At the same time, a $0.1 \mathrm{~cm}$-sized papillary microcarcinoma was found in the right lobe of the thyroid, which showed strong-positivity for BRAF V600E via IHC staining (Fig. 4f). Serum IgG4 level was checked only postoperatively, 2 years after the surgery, which was 42.8 $\mathrm{mg} / \mathrm{dL}$ (normal range: $3.9-86.4 \mathrm{mg} / \mathrm{dL}$ ).

\section{Discussion}

Parathyroid adenoma with prominent lymphocytic infiltrate is a rare condition. Including the present case, 12 patients have been reported (Table 1) [1-6]. The median age was 58 years old (range, 29-74) with slight female predominance (male:female $=1: 1.4$ ). Some patients $(n=4)$ suffered from renal colic [1], hypertension [1], duodenal ulcer [3], or osteopenia [4], which were probably associated with hyperparathyroidism [7]. Otherwise, patients were asymptomatic $(n=8)$. The location of parathyroid adenoma with prominent lymphocytic infiltrate was primarily orthotopic $(n=11)$ without predilection for sites. Exceptionally, one patient had a heterotopic tumor in the anterior mediastinum $(n=$ 1) [5]. The mean diameter was $1.9 \pm 1.1 \mathrm{~cm}$ (mean \pm standard deviation). Most patients $(n=11)$ had no history of autoimmune disease, except for one who had ten years of psoriasis [1]. Four patients had concomitant thyroid diseases, including nodular goiter $(n=3)[2,4]$ or PTC ( $n=1$, present). Two patients had received chemotherapy for breast cancer before diagnosis $[2,4]$.

The histopathologic features of the present patient were compatible to those of the previous reports (Table 1) [1-6]. Numerous inflammatory cells were composed of predominantly lymphocytes, forming germinal cen- 

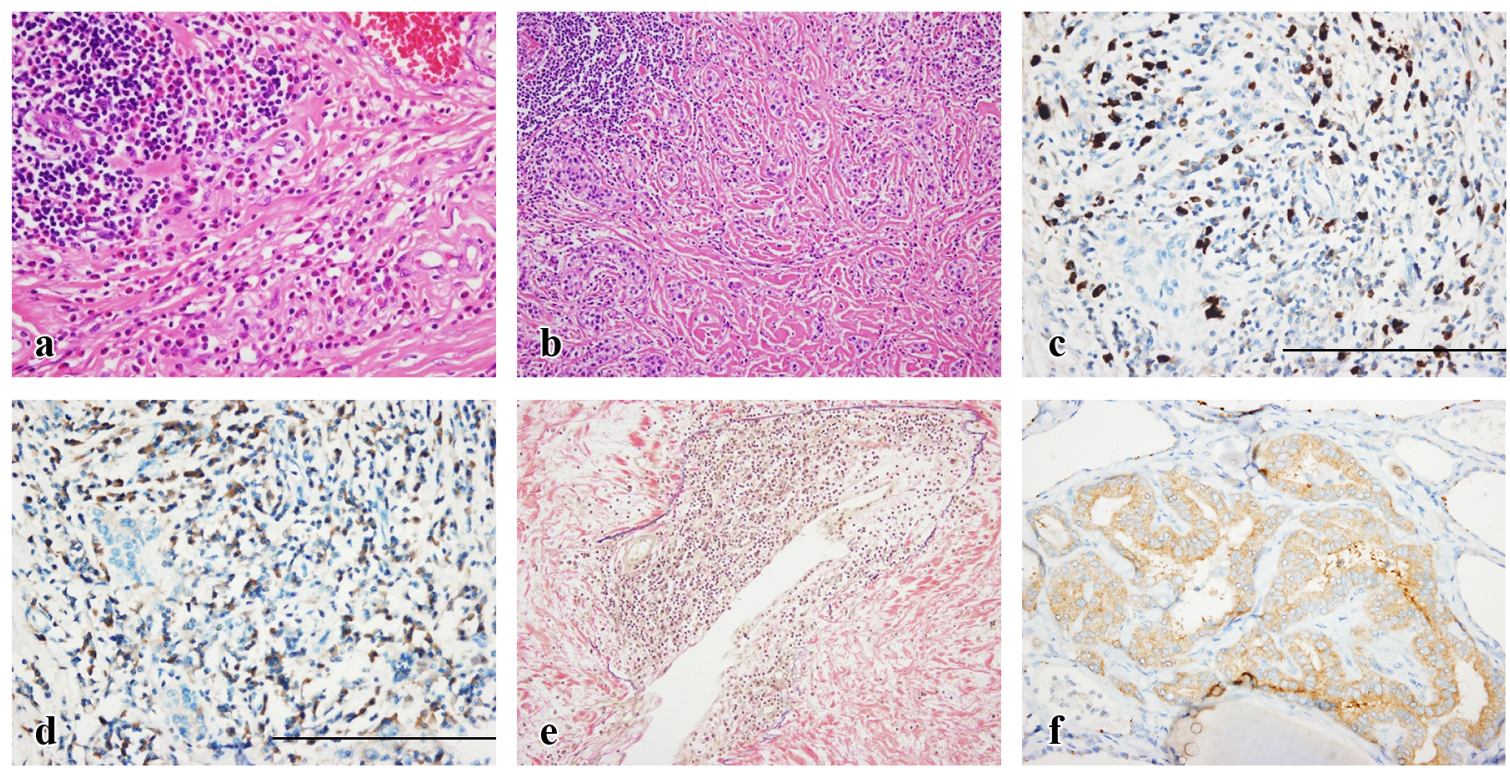

Fig. 4 Inflammatory infiltrate contains lymphocytes, plasma cells, and some eosinophils (a). Storiform-type fibrosis is observed vaguely (b). In a high-power field, $>100$ plasma cells positive for IgG4 are found (c), which are approximately $40-60 \%$ of IgG-positive plasma cells in the serial section (scale bar $=10 \mu \mathrm{m})(\mathrm{d})$. Lymphocytes and plasma cells infiltrate into the venous wall that is apparent on elastin staining, inducing obliterative phlebitis (e). Apart from the adenoma, a papillary microcarcinoma was found in the contralateral lobe of the thyroid, which expressed the BRAF V600E mutant protein (f).

ters, along with some eosinophils and plasma cells. Infiltrating lymphocytes were composed of mixed T- and B-cells $(\mathrm{CD} 3: \mathrm{CD} 20=1.5: 1)$ with a similar CD4-to-CD8 T-cell ratio (figure not shown), which is dissimilar to the predominance of CD4-positive T-cells in Hashimoto thyroiditis [8]. Germinal center architectures were wellpreserved. Moreover, the absence of atypical lymphoid cells, lymphoepithelial lesion [6], or in situ hybridization reactivity to Epstein-Barr virus (figure not shown) excluded the possibility of parathyroid lymphoma, a very rare but worrisome disease [9]. PD-1/PD-L1 interaction is an immune-checkpoint that regulates inflammatory reaction $[10,11]$. The low PD-L1 expression of tumor cells of parathyroid adenoma with prominent lymphocytic infiltrate was hypothesized to reflect a low level of immune-evasion or immune-tolerance of the tumor cells [10]. In addition, the high PD-L1 expression of stromal lymphocytes was in line with the idea that the immunosuppressive inflammatory cells were ineffective in chronic inflammatory disorders [11].

Thick banding fibrosis, trabecular arrangement of atypical epithelial cells, and marked enlargement of adenoma were distinct features in this case. These features raised the possibility of atypical parathyroid adenoma, an entity intermediate between parathyroid adenoma and carcinoma [12]. In this patient, nevertheless, the absence of mitosis and the low Ki-67 index of tumor cells, which was much lower than that of previous reports $(3.9 \%)$ on atypical parathyroid adenoma [13], suggested the benign nature of the present case. However, atypical parathyroid adenomas with $<1 \% \mathrm{Ki}-67$ index have also been reported $[14,15]$. Because the malignant potential of parathyroid adenoma with prominent lymphocytic infiltrate is not known, further study is needed. The patient has been regularly followed up for 3 years after surgery without local recurrence or distant metastasis.

Notably, this case mimicked PTC in cytology and in needle biopsy specimens. The microfollicular architecture of cells observed in the aspiration cytology was misinterpreted as thyroid neoplasm, or atypia of unknown significance. Nuclear atypia, which may have been associated with inflammatory reactions, made cytologic diagnosis more challenging because it is rare in parathyroid lesions [16]. In the needle biopsy, the trabecular structure of epithelial cells embedded in the abundant fibrotic stroma and relatively irregular nuclei with oncocytic cytoplasm resembled infiltrating carcinoma. Moreover, IHC staining for HBME-1 was diffuse-positive in tumor cells. Even though HBME-1 is a useful marker in diagnosing thyroid carcinoma, its sensitivity and specificity have been variable among studies and cautions regarding its interpretation should be taken [17-19]. Previously, $11.9 \%$ of parathyroid adenomas expressed HBME-1 [14]. Therefore, it is necessary to enlist parathyroid adenoma with prominent lymphocytic infiltrate on the differential diagnoses of PTC in aspiration cytology or needle biopsy, especially when patients have hyperparathyroidism and supportive results on imaging work-ups. 
Table 1 Clinicopathologic features of parathyroid adenoma with prominent lymphocytic infiltrate in the literature

\begin{tabular}{|c|c|c|c|c|c|c|c|}
\hline \multirow[b]{2}{*}{ Age/sex } & \multirow[b]{2}{*}{$\begin{array}{c}\mathrm{Ca}^{2+} \\
(\mathrm{mg} / \mathrm{dL})\end{array}$} & \multirow[b]{2}{*}{$\begin{array}{c}\text { PTH } \\
(n \times \mathrm{ULN})\end{array}$} & \multirow[b]{2}{*}{$\begin{array}{c}\text { Sign/ } \\
\text { symptom }\end{array}$} & \multirow[b]{2}{*}{$\begin{array}{l}\text { Site/size } \\
(\mathrm{cm})\end{array}$} & \multicolumn{2}{|c|}{ Microscopic features } & \multirow[b]{2}{*}{$\begin{array}{l}\text { Underlying } \\
\text { disease }\end{array}$} \\
\hline & & & & & $\begin{array}{l}\text { Unusual } \\
\text { morphologic } \\
\text { findings }\end{array}$ & Inflammatory cells & \\
\hline $74 / \mathrm{F}[1]$ & 11.5 & 1.9 & Renal colic & n.a./1.4 & $\begin{array}{l}\text { Pleomorphism, } \\
\text { encapsulation }\end{array}$ & Lym + His, GC & None \\
\hline 44/M [1] & 11.6 & 2.2 & HTN & n.a. $/ 0.5$ & $\begin{array}{l}\text { Fibrotic stroma, } \\
\text { Atrophy }\end{array}$ & $\begin{array}{l}\mathrm{Lym}+\mathrm{Pla}+\mathrm{His}, \\
\mathrm{GC}\end{array}$ & DM, Psoriasis \\
\hline $68 / \mathrm{F}[2]$ & 10.6 & n.a. & None & $\mathrm{LU} / 2.5$ & None & Lym + Pla, GC & Meniere's disease \\
\hline $59 / \mathrm{F}[2]$ & n.a. & n.a. & None & n.a./n.a. & None & Lym & Nodular goiter \\
\hline $60 / \mathrm{M}[2]$ & 10.6 & 1.1 & None & $\mathrm{LU} / 1.5$ & None & Lym, GC & None \\
\hline $59 / \mathrm{F}[2]$ & n.a. & n.a. & None & $\mathrm{RU} / 3.5$ & None & Lym + Pla, GC & $\begin{array}{l}\text { Breast cancer, } \\
\text { Nodular goiter }\end{array}$ \\
\hline $70 / \mathrm{F}[3]$ & 12.7 & 3.0 & None & $\mathrm{RU} / 2.0$ & None & $\begin{array}{l}\mathrm{Lym}+\mathrm{Pla}+\mathrm{His}, \\
\mathrm{CD} 4: \mathrm{CD} 8=3: 1\end{array}$ & $\begin{array}{l}\text { A.fib, Nodular } \\
\text { goiter }\end{array}$ \\
\hline 48/M [3] & 14.7 & n.a. & DU & $\mathrm{Rt} / 0.6$ & None & $\begin{array}{l}\mathrm{Lym}+\mathrm{Pla}+\mathrm{His}, \\
\mathrm{CD} 4: \mathrm{CD} 8=3: 1\end{array}$ & $\begin{array}{l}\text { Schizophrenia, } \\
\text { CVA }\end{array}$ \\
\hline $43 / \mathrm{F}[4]$ & $10.6^{\mathrm{a}}$ & $0.9^{\mathrm{a}}$ & Osteopenia & $\mathrm{RL} / 1.7$ & $\begin{array}{l}\text { Fibrotic stroma, } \\
\text { encapsulation }\end{array}$ & $\mathrm{Lym}+\mathrm{Pla}+\mathrm{His}$ & Breast cancer \\
\hline 29/M [5] & n.a. & 3.7 & None & Mediastinum/1.4 & Atypism & Lym & None \\
\hline $52 / \mathrm{F}[6]$ & n.a. & n.a. & None & $\mathrm{RL} / 1.9$ & $\begin{array}{l}\text { Encapsulation, } \\
\text { Gland destruction }\end{array}$ & Lym + Pla, GC & None \\
\hline $\begin{array}{l}\text { 57/M } \\
\text { [Present] }\end{array}$ & 12.2 & 3.9 & None & $\mathrm{LU} / 3.9$ & $\begin{array}{l}\text { Fibrotic stroma, } \\
\text { atypism, } \\
\text { pleomorphism }\end{array}$ & $\begin{array}{l}\text { Lym + Eo + Pla, } \\
\text { GC }\end{array}$ & PTC \\
\hline
\end{tabular}

ULN, upper limit of normal; n.a., not available; Lym, lymphocyte; His, histiocyte; GC, germinal center; HTN, hypertension; Pla, plasma cell; DM, diabetes mellitus; LU, left upper; RU, right upper; A.fib, atrial fibrillation; DU, duodenal ulcer; Rt, right; CVA, cerebrovascular accident; RL, right lower; Eo, eosinophil; PTC, papillary thyroid carcinoma

${ }^{a}$ The patient was taking sodium alendronate for osteopenia

Dense infiltration of lymphocytes as well as eosinophils, an increased number of IgG4-positive plasma cells with increased $\mathrm{IgG} 4 / \mathrm{IgG}-$ positive plasma cell ratio, together with storiform-type fibrosis and obliterative phlebitis are typical histopathological features of IgG4$\mathrm{RD}$, a fibroinflammatory disorder involving almost all organs [20]. The number of IgG4-positive plasma cell and its ratio to IgG-positive plasma cell are 10-200/highpower field and $>40 \%$, respectively, in IgG4-RD [21]. Clinically, the disease commonly manifests as a mass lesion with or without systemic symptoms [21]. Many distinct inflammatory disorders, for example Riedel thyroiditis, have been revealed to be closely connected to IgG4-RD [21, 22]. Although its involvement in the parathyroid gland has not been reported and supportive clinical information, for example serum IgG4 level, was not evaluated in this patient before the operation, the characteristic histopathological features observed in this patient indicate that the tumor of this patient has the features of IgG4-RD [20]. There was no evidence of disease involvement in other organs on the neck region. The postoperative serum IgG4 level was within the normal range, which might have decreased after the curative resection. Alternatively, it might have been within normal limits at the presentation because serum IgG4 concentration is neither sufficiently sensitive nor specific for IgG4-RD [23]. Moreover, some of previous reports on parathyroid adenoma with prominent lymphocytic infiltrate described stromal fibrosis $[1,4]$ and infiltration of plasma cells $[1-4,6]$ that were reminiscent of IgG4-RD, which raises the possibility that parathyroid adenoma with prominent lymphocytic infiltrate is actually parathyroid adenoma with IgG4-RD features. IgG4-RD usually decreases the functions of the involved organs by inducing scar-like fibrosis, e.g. Riedel thyroiditis or autoimmune pancreatitis [22]. However, organ-stimulatory effect of IgG4 was described in a portion of Graves' disease [24, 25]. Including the present case, five patients with parathyroid adenoma with prominent lymphocytic infiltrate were reported to have hyperparathyroidism (Table 
1) $[1,3,5]$. It is possible that IgG4 in the parathyroid glands of these patients acted as a parathyroidstimulating immunoglobulin on the affected parathyroid gland that would promote the secretion of PTH and the proliferation of parathyroid chief cell. However, given that the other remnant parathyroid glands showed no evidence of hyperplasia in all cases, we should also consider the possibility that certain parathyroid adenomas may expose the neoantigen which provokes the immunologic reactions similar to those of IgG4-RD [26].

To confirm that hypothesis, it should be followed by the retrospective studies with more cases in the future.

\section{Disclosure}

None of the authors have any potential conflicts of interest associated with this case report.

\section{Ethics}

All procedures performed in studies involving human participants were in accordance with the ethical standards of the institutional review board of Seoul National University Hospital (IRB number H-1803-082-930) and with the 1964 Helsinki declaration and its later amendments or comparable ethical standards.

\section{Acknowledgments}

This study was funded by the National Research Foundation of Korea (NRF) grants funded by the Korea Government, the Ministry of Science, ICT \& Future Planning (2015M3A9A7067220, 2014R1A2A1A10052404, 2013 M3C8A1078501, and 2013M3A9A7046303) and grant from the Seoul National University Hospital (SNUH) Research Fund (No. 03-2016-0440).

\section{References}

1. Veress B, Nordenstrom J (1994) Lymphocytic infiltration and destruction of parathyroid adenomas: a possible tumour-specific autoimmune reaction in two cases of primary hyperparathyroidism. Histopathology 25: 373-377.

2. Lawton TJ, Feldman M, LiVolsi VA (1998) Lymphocytic infiltrates in solitary parathyroid adenomas: a report of four cases with review of the literature. Int J Surg Pathol 6: 5-9.

3. Lam KY, Chan AC, Lo CY (2000) Parathyroid adenomas with pronounced lymphocytic infiltration: no evidence of autoimmune pathogenesis. Endocr Pathol 11: 77-83.

4. Kovacs K, Bell CD, Juco J, Rotondo F, Anderson J (2007) Parathyroid chief cell adenoma associated with massive chronic parathyroiditis in a woman with hyperparathyroidism. Endocr Pathol 18: 42-45.

5. Fallone E, Bourne PA, Watson TJ, Ghossein RA, Travis $\mathrm{WD}$, et al. (2009) Ectopic (mediastinal) parathyroid adenoma with prominent lymphocytic infiltration. Appl Immunohistochem Mol Morphol 17: 82-84.

6. Iliadis A, Koletsa T, Kostopoulos I, Karayannopoulou G (2015) Parathyroid adenoma with prominent lymphocytic infiltrate. Case Rep Pathol 2015: 705843.

7. Bilezikian JP, Bandeira L, Khan A, Cusano NE (2018) Hyperparathyroidism. Lancet 391: 168-178.

8. Antonelli A, Ferrari SM, Corrado A, Di Domenicantonio A, Fallahi P (2015) Autoimmune thyroid disorders. Autoimmun Rev 14: 174-180.

9. Erickson LA (2012) Chronic parathyroiditis. In: Nosé V, Erickson LA, Tischler AS, Asa SL, Lopes MBS (eds) Diagnostic pathology: endocrine $\left(1^{\text {st }}\right)$. AMIRSYS, Salt Lake City: 2-24-2-27.

10. Weyand CM, Berry GJ, Goronzy JJ (2018) The immunoinhibitory PD-1/PD-L1 pathway in inflammatory blood vessel disease. J Leukoc Biol 103: 565-575.

11. Mezache L, Magro C, Hofmeister C, Pichiorri F, Sborov $\mathrm{D}$, et al. (2017) Modulation of PD-L1 and CD8 activity in idiopathic and infectious chronic inflammatory conditions. Appl Immunohistochem Mol Morphol 25: 100-109.

12. DeLellis RA, Arnold A, Eng C, Erickson LA, Franssila KO, et al. (2017) Parathyroid adenoma. In: Lloyd RV, Osamura RY, Klöppel G, Rosai J (eds) WHO classification of Tumours of Endocrine Organs $\left(4^{\text {th }}\right)$. IARC, Lyon: $153-158$.

13. Quinn CE, Healy J, Lebastchi AH, Brown TC, Stein JE, et al. (2015) Modern experience with aggressive parathyroid tumors in a high-volume New England referral center. $J$ Am Coll Surg 220: 1054-1062.

14. Karaarslan S, Yurum FN, Kumbaraci BS, Pala EE, Sivrikoz ON, et al. (2015) The role of parafibromin, galectin-3, HBME-1, and Ki-67 in the differential diagnosis of parathyroid tumors. Oman Med J 30: 421-427.

15. Hosny Mohammed K, Siddiqui MT, Willis BC, Zaharieva Tsvetkova D, Mohamed A, et al. (2017) Parafibromin, APC, and MIB-1 are useful markers for distinguishing parathyroid carcinomas from adenomas. Appl Immunohistochem Mol Morphol 25: 731-735.

16. Cho M, Oweity T, Brandler TC, Fried K, Levine P (2017) Distinguishing parathyroid and thyroid lesions on ultrasound-guided fine-needle aspiration: a correlation of clinical data, ancillary studies, and molecular analysis. Cancer Cytopathol 125: 674-682.

17. de Matos LL, Del Giglio AB, Matsubayashi CO, de Lima Farah M, Del Giglio A, et al. (2012) Expression of CK-19, galectin-3 and HBME-1 in the differentiation of thyroid lesions: systematic review and diagnostic meta-analysis. Diagn Pathol 7: 97. 
18. Barut F, Onak Kandemir N, Bektas S, Bahadir B, Keser S, et al. (2010) Universal markers of thyroid malignancies: galectin-3, HBME-1, and cytokeratin-19. Endocr Pathol 21: $80-89$.

19. Zhu X, Sun T, Lu H, Zhou X, Lu Y, et al. (2010) Diagnostic significance of CK19, RET, galectin-3 and HBME-1 expression for papillary thyroid carcinoma. $J$ Clin Pathol 63: 786-789.

20. Deshpande V, Zen Y, Chan JK, Yi EE, Sato Y, et al. (2012) Consensus statement on the pathology of IgG4related disease. Mod Pathol 25: 1181-1192.

21. Weindorf SC, Frederiksen JK (2017) IgG4-related disease a reminder for practicing pathologists. Arch Pathol Lab Med 141: 1476-1483.

22. Stan MN, Sonawane V, Sebo TJ, Thapa P, Bahn RS (2017) Riedel's thyroiditis association with IgG4-related disease. Clin Endocrinol (Oxf) 86: 425-430.
23. Hao M, Liu M, Fan G, Yang X, Li J (2016) Diagnostic value of serum IgG4 for IgG4-related disease: a PRISMAcompliant systematic review and meta-analysis. Medicine (Baltimore) 95: e3785.

24. Takeshima K, Inaba H, Furukawa Y, Nishi M, Yamaoka $\mathrm{H}$, et al. (2014) Elevated serum immunoglobulin G4 levels in patients with Graves' disease and their clinical implications. Thyroid 24: 736-743.

25. Hiratsuka I, Yamada H, Itoh M, Shibata M, Takayanagi T, et al. (2018) Changes in serum immunoglobulin G4 levels in patients with newly diagnosed Graves' disease. Exp Clin Endocrinol Diabetes [Epub ahead of print]. doi: 10.1055/a-0669-9333.

26. Joseph CG, Darrah E, Shah AA, Skora AD, CasciolaRosen LA, et al. (2014) Association of the autoimmune disease scleroderma with an immunologic response to cancer. Science 343: 152-157. 